\title{
Clinical and radiological outcomes of spinal endoscopic discectomy-assisted oblique lumbar interbody fusion: preliminary results
}

\author{
Dong Hwa Heo, MD, PhD, ${ }^{1}$ and Jin-Sung Kim, MD, PhD² \\ ${ }^{1}$ Department of Neurosurgery, Spine Center, The Leon Wiltse Memorial Hospital, Suwon; and 2Department of Neurosurgery, \\ Seoul St. Mary's Hospital, College of Medicine, The Catholic University of Korea, Seoul, South Korea
}

\begin{abstract}
OBJECTIVE Direct neural decompression cannot be achieved by performing lateral lumbar interbody fusion (LLIF). To overcome the indirect decompressive effect of LLIF, additional endoscopic discectomy with oblique lumbar interbody fusion (OLIF) has been attempted. The purpose of this study was to assess the clinical and radiological outcomes of patients who underwent OLIF with additional endoscopic discectomy.

METHODS Spinal endoscopic discectomy-assisted OLIF was attempted to remove herniated disc material. Only patients with a follow-up time that exceeded 12 months were enrolled. Clinical parameters examined were the Oswestry Disability Index and visual analog scale scores of back and leg pain. Postoperative MRI was also performed.

RESULTS Fourteen patients were enrolled. Central and foraminal disc herniations were evident in 8 and 6 patients, respectively. Concomitant central or foraminal herniated discs were removed completely after additional endoscopic discectomy, and disc removal was confirmed by postoperative MRI. Mean preoperative visual analog scale scores and Oswestry Disability Index scores improved postoperatively.
\end{abstract}

CONCLUSIONS OLIF with additional endoscopic discectomy results in successful direct neural decompression without posterior decompressive procedures. Endoscopic assistance might overcome the limitations of LLIF.

https://thejns.org/doi/abs/10.3171/2017.5.FOCUS17196

KEY WORDS lumbar disc disease; endoscopy; discectomy; stenosis; oblique lumbar interbody fusion

$\mathrm{L}$ UMBAR interbody fusion surgery is a common and effective treatment for lumbar degenerative disease. ${ }^{5,11,14}$ Minimally invasive spinal fusion surgeries, such as mini-anterior lumbar interbody fusion (ALIF) and transforaminal lumbar interbody fusion (TLIF), are performed to minimize the injury to posterior lumbar myoligamentous structures. Minimally invasive lateral lumbar interbody fusion (LLIF) surgeries, such as direct lateral interbody fusion (DLIF) and oblique lumbar interbody fusion (OLIF), have been attempted recently to treat lumbar degenerative disease. .,6,10,17 Compared with posterior lumbar interbody fusion or TLIF, LLIF cannot result in direct decompression as is seen in posterior fusion surgery. Indirect decompression effects caused by reduction of spondylolisthesis and disc space widening, as with
ALIF, are observed with LLIF., ${ }^{2,412,13}$ Disc height restoration by LLIF results in foraminal widening. ${ }^{12,13}$ Therefore, because LLIF is not feasible for direct decompression, it has limited indications for severe canal stenosis or concomitant ruptured disc herniation. ${ }^{2}$

We recently attempted adding endoscopic discectomy to OLIF before insertion of the fusion cage. Because OLIF procedures are performed with the patient in the left true lateral decubitus position, an endoscopic system can reach right foraminal and central canal lesions., ${ }^{2,7}$ Therefore, by using a spinal endoscopic device, concomitant central and foraminal ruptured disc material can be effectively removed during OLIF. ${ }^{2}$ The purpose of our study was to assess the clinical and radiological outcomes of patients after additional endoscopic discectomy with OLIF.

ABBREVIATIONS ALIF = anterior lumbar interbody fusion; DLIF = direct lateral interbody fusion; LLIF = lateral lumbar interbody fusion; ODI = Oswestry Disability Index; OLIF = oblique lumbar interbody fusion; TLIF = transforaminal lumbar interbody fusion.

SUBMITTED March 31, 2017. ACCEPTED May 11, 2017.

INCLUDE WHEN CITING DOI: 10.3171/2017.5.FOCUS17196. 


\section{Methods}

Since May 2013, we have performed the OLIF procedure on 265 patients. Of these patients, 16 underwent OLIF with additional endoscopic discectomy. Fourteen patients with a follow-up time that exceeded 12 months were enrolled for this study.

\section{Indications for OLIF}

Indications for endoscopically assisted OLIF were instability or foraminal stenosis with a concomitant herniated lumbar disc (Fig. 1). Patients with resting radicular pain were considered to have a foraminal or central herniated disc and were included for OLIF with endoscopic discectomy. ${ }^{2,7}$ Other indications included lumbar segmental instability with dural compression by a central herniated lumbar disc, lumbar segmental instability with right foraminal disc herniation, degenerative lumbar spondylolisthesis with right foraminal or central disc herniation, intervertebral foraminal stenosis with right foraminal or central disc herniation, and central stenosis with right foraminal or central disc herniation (Fig. 1).

\section{Operative Procedures}

After induction of general anesthesia, OLIF was performed with the patient in the left true lateral decubitus position on a radiolucent operating table. Routine OLIF, including blind discectomy, progressed after muscle dissection and retractor application. After blind discectomy and OLIF, endoscopic systems for percutaneous endoscopic lumbar discectomy were applied to the blind-discectomy field.

First, we examined the condition of the endplate preparation for fusion using a spinal endoscopic view. If much remnant disc material and the cartilaginous endplate were noted, endplate preparation was repeated after endoscopic discectomy using a curette and a shaver. Additional endoscopic procedures were performed using real-time $\mathrm{C}$-arm fluoroscopic guidance (Fig. 2). We used an endoscope with a working channel and 2 irrigation channels, which usually is used for percutaneous endoscopic lumbar discectomy. The posterior portion of the disc (central disc herniation) was removed using semiflexible endoscopic forceps under endoscopic magnetic visualization until identification of the posterior longitudinal ligament or ventral side of the dura mater. On occasion, the posterior longitudinal ligament was resected to explore the epidural space. In cases of foraminal disc herniation, the left side of the neural foramen was explored using an endoscope to remove foraminal ruptured disc particles. If remnant disc materials were detected on the endplate in the endoscopic view, endplate preparation was repeated before cage insertion.

Last, an allograft-filled cage for lateral interbody fusion was inserted using $\mathrm{C}$-arm fluoroscopic guidance. Percutaneous pedicle screw fixation was performed after OLIF (Fig. 3).

\section{Analysis of Radiological and Clinical Parameters}

We enrolled patients who had undergone OLIF with endoscopic discectomy and whose follow-up time exceeded 12 months. Clinical parameters that we investigated

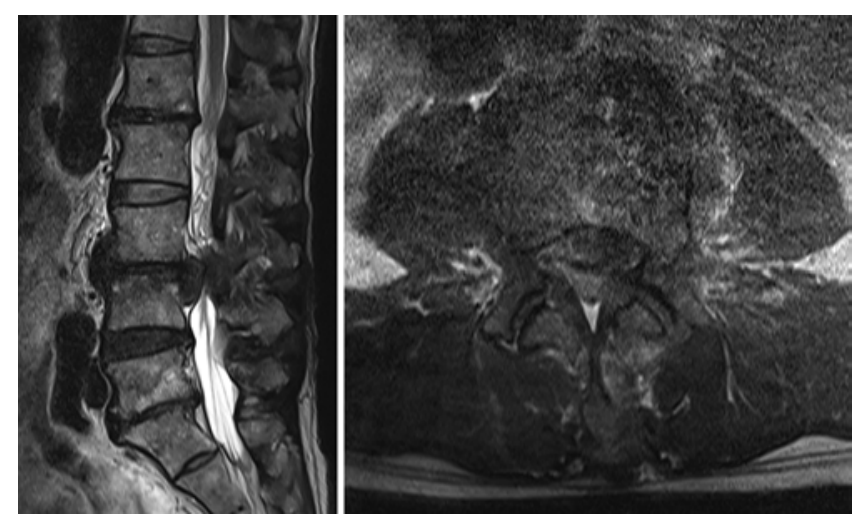

FIG. 1. A 50-year-old male patient presented with severe radiating pain in both legs. Sagittal (left) and axial (right) MR images show central stenosis with a ruptured disc at the L3-4 level. The ruptured disc is compressing the dural sac severely.

included the Oswestry Disability Index (ODI), ${ }^{1}$ operative time, follow-up period, estimated blood loss, and procedure-related complications. The radiological parameters that we analyzed were diagnosis, operative level(s), central canal diameter, disc height, foraminal height, segmental lordotic angle of operation, and whole lumbar lordosis. Optimal disc-removal status, foraminal height, and central canal diameter were measured by using preoperative and postoperative MRI (Fig. 3A). Foraminal height was measured using T2-weighted parasagittal MRI, which documents the intervertebral neural foramen. The central canal diameter was measured using T2-weighted midsagittal MRI. The whole lumbar lordotic angle, segmental lordotic angle of operative segments, and disc height of operative segments were measured using preoperative and postoperative radiography. Whole lumbar lordosis was measured as the angle between the upper endplate of L-1 and the upper endplate of S-1. The segmental lordotic angle of operation segments was measured as the angle between the upper endplate of the upper vertebral body and the lower endplate of the lower vertebral body.

This investigation was conducted in accordance with our institutional guidelines and complied with international laws and policies, with IRB approval from The Leon Wiltse Memorial Hospital Institutional Review Board.
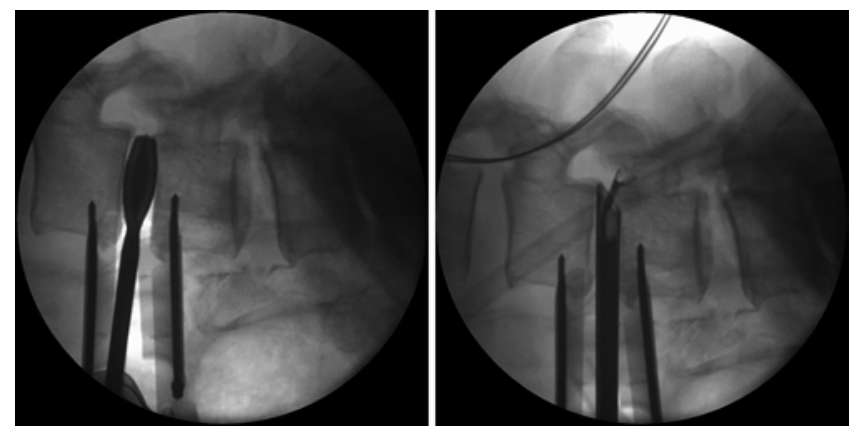

FIG. 2. Intraoperative fluoroscopic images of endoscopically assisted OLIF. After blind discectomy (left), the endoscopic device is applied through the retractor. Endoscopic discectomy is performed under $\mathrm{C}$-arm fluoroscopic guidance (right). 


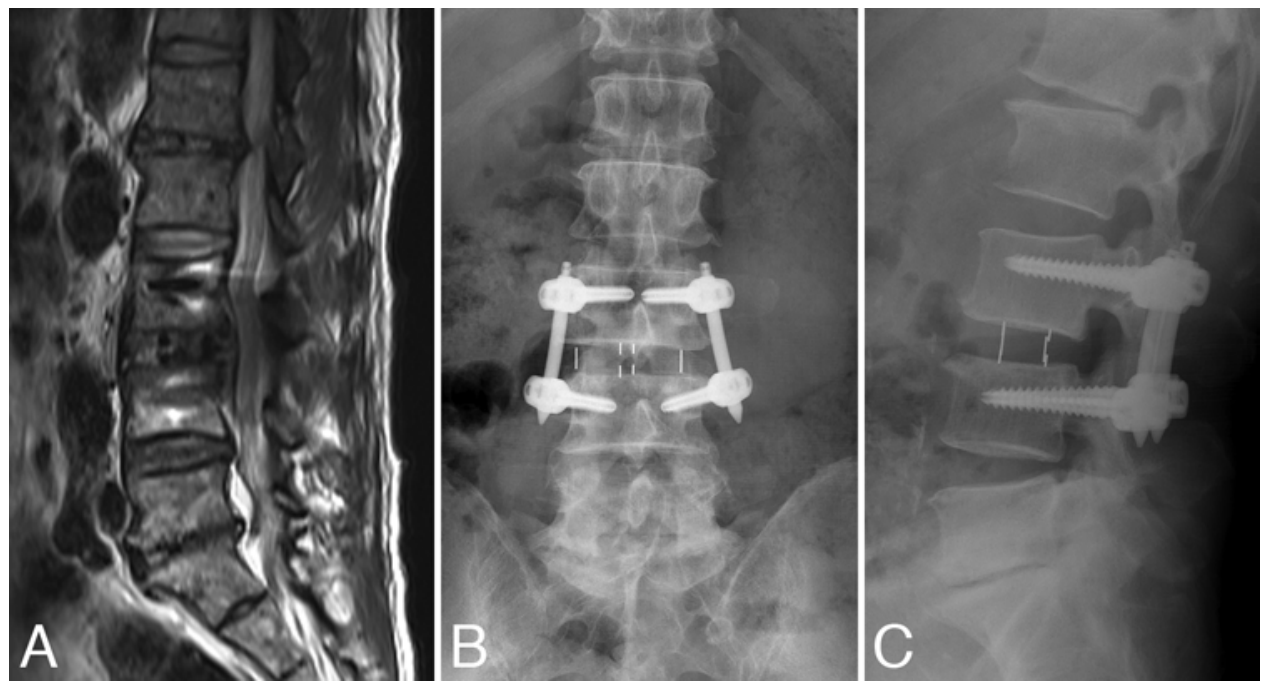

FIG. 3. A: Postoperative MR image reveals complete decompression and removal of herniated disc material at L3-4. B and C: After the OLIF procedure, percutaneous pedicle screws were inserted.

Statistical analysis was performed with R 3.1.2 for Windows, using the Wilcoxon rank-sum test. A statistically significant result was considered to be $\mathrm{p}<0.05$.

\section{Results}

The mean \pm SD age of the 14 patients ( 8 women, 6 men) was $66.3 \pm 8.8$ years. The mean follow-up time was $15.3 \pm$ 5.3 months. Operative levels were distributed from L2 -3 to L4-5 (Table 1). Two-level fusion was performed in 4 patients, and 1-level fusion was performed in 10 patients (Table 1). The mean estimated blood loss, including the amount of drainage blood, was $105.5 \pm 20.9 \mathrm{ml}$, and the mean operative time for 1-level fusions was $155.8 \pm 45.1$ minutes.

Central disc herniation was found in 8 patients, and 6 patients had foraminal disc herniation (Table 1). Concomitant central or foraminal herniated discs were removed completely after additional endoscopic discectomy. Disc removal was confirmed by postoperative MRI (Fig. 3). The mean preoperative central canal diameter $(5.1 \pm 1.3$ $\mathrm{mm}$ ) increased significantly to $9.6 \pm 2.1 \mathrm{~mm}$ postoperatively $(\mathrm{p}<0.05)$. The right foramen height also increased significantly postoperatively, from a mean of $17.4 \pm 2.2$ to one of $20.1 \pm 2.4 \mathrm{~mm}(\mathrm{p}<0.05)$. At the final follow-up visit, significant increases in the mean contralateral left foramen height $(17.8 \pm 4.1$ to $19.9 \pm 3.3 \mathrm{~mm})$ and disc height $(8.6 \pm 1.7$ to $13.3 \pm 1.9 \mathrm{~mm})$ were evident (both $\mathrm{p}<0.05$ ). A significant postoperative increase was observed also in mean segmental lordotic angle $\left(5.3^{\circ} \pm 4.3^{\circ}\right.$ to $\left.8.3^{\circ} \pm 2.8^{\circ}\right)$ and whole lumbar lordosis $\left(20.7^{\circ} \pm 8.6^{\circ}\right.$ to $\left.33.4^{\circ} \pm 5.3^{\circ}\right)$ (both $\mathrm{p}<0.05$ ) (Table 2).

Poor endplate preparation status was seen in patients during additional endoscopic discectomy. Endplate preparation was repeated in 2 patients who had substantial amounts of remnant cartilaginous endplate material after the blind discectomy.

The mean preoperative ODI value improved from 42.5 \pm 11.8 to $13.4 \pm 10.1$ postoperatively $(\mathrm{p}<0.05)$ (Table 2 ) The patients experienced no serious complications associated with their surgery. Transient leg numbness occurred
TABLE 1. Summary of demographic and diagnostic data in 14 patients

\begin{tabular}{|c|c|c|c|c|}
\hline $\begin{array}{l}\mathrm{Pt} \\
\text { No. }\end{array}$ & Sex & $\begin{array}{l}\text { Age } \\
\text { (yrs) }\end{array}$ & Diagnosis & Level \\
\hline 1 & $\mathrm{~F}$ & 62 & $\begin{array}{l}\text { Degenerative spondylolisthesis w/ } \\
\text { central HNP }\end{array}$ & L4-5 \\
\hline 2 & $\mathrm{~F}$ & 70 & $\begin{array}{l}\text { Degenerative spondylolisthesis w/ } \\
\text { central HNP }\end{array}$ & L3-4 \\
\hline 3 & M & 68 & $\begin{array}{l}\text { Foraminal HNP w/ instability, adjacent- } \\
\text { segment degeneration after previous } \\
\text { L4-5 fusion }\end{array}$ & L3-4 \\
\hline 4 & M & 76 & $\begin{array}{l}\text { Degenerative spondylolisthesis w/ } \\
\text { foraminal HNP }\end{array}$ & L3-5 \\
\hline 5 & M & 72 & $\begin{array}{l}\text { Degenerative spondylolisthesis w/ } \\
\text { central HNP }\end{array}$ & L4-5 \\
\hline 6 & M & 53 & $\begin{array}{l}\text { Spinal stenosis w/ central HNP, cauda } \\
\text { equina syndrome }\end{array}$ & L2-3 \\
\hline 7 & $\mathrm{~F}$ & 70 & $\begin{array}{l}\text { Degenerative spondylolisthesis w/ } \\
\text { central HNP }\end{array}$ & L4-5 \\
\hline 8 & $\mathrm{~F}$ & 75 & $\begin{array}{l}\text { Degenerative spondylolisthesis w/ } \\
\text { foraminal HNP }\end{array}$ & L2-4 \\
\hline 9 & M & 58 & $\begin{array}{l}\text { Degenerative spondylolisthesis w/ } \\
\text { central HNP }\end{array}$ & L3-4 \\
\hline 10 & $\mathrm{~F}$ & 83 & Spinal stenosis w/ foraminal HNP & L3-5 \\
\hline 11 & $\mathrm{~F}$ & 59 & $\begin{array}{l}\text { Degenerative spondylolisthesis w/ } \\
\text { foraminal HNP }\end{array}$ & L4-5 \\
\hline 12 & $\mathrm{~F}$ & 65 & $\begin{array}{l}\text { Spinal stenosis w/ central HNP, cauda } \\
\text { equina syndrome }\end{array}$ & L2-3 \\
\hline 13 & M & 50 & Spinal stenosis w/ huge central HNP & L3-4 \\
\hline 14 & $\mathrm{~F}$ & 62 & Foraminal HNP w/ foraminal stenosis & L3-5 \\
\hline
\end{tabular}

$\mathrm{HNP}=$ herniated nucleus pulposus; $\mathrm{Pt}=$ patient. 
TABLE 2. Clinical and radiological results

\begin{tabular}{lcc}
\hline \multicolumn{1}{c}{ Parameter } & Preop & Postop \\
\hline ODI score & $42.5 \pm 11.8$ & $13.4 \pm 10.1$ \\
\hline Central canal diameter $(\mathrm{mm})$ & $5.1 \pm 1.3$ & $9.6 \pm 2.1$ \\
\hline Foramen height $(\mathrm{mm})$ & & \\
\hline Right & $17.4 \pm 2.2$ & $20.1 \pm 2.4$ \\
\hline Left & $17.8 \pm 4.1$ & $19.9 \pm 3.3$ \\
\hline Disc height $(\mathrm{mm})$ & $8.6 \pm 1.7$ & $13.3 \pm 1.9$ \\
\hline Segmental lordotic angle $\left(^{\circ}\right)$ & $5.3 \pm 4.3$ & $8.3 \pm 2.8$ \\
\hline Whole lumbar lordotic angle $\left(^{\circ}\right)$ & $20.7 \pm 8.6$ & $33.4 \pm 5.3$ \\
\hline
\end{tabular}

Values are presented as the mean $\pm S D$.

in 2 patients, and postoperative cage subsidence ( $>2 \mathrm{~mm}$ ) had occurred in 2 patients by their final follow-up visit. The outcome of the 2 patients in whom cage subsidence occurred was satisfactory.

\section{Discussion}

LLIF, such as OLIF or DLIF, is a minimally invasive spinal surgery for the treatment of lumbar degenerative disease. ${ }^{13,16,17}$ Although the preservation of posterior lumbar structures, such as muscle, ligamentous structures, laminas, and facet joints, is a compelling benefit of LLIF, the resulting indirect decompression is a drawback and limits the lateral approach. The indirect decompressive effect of LLIF results in disc height restoration and reduction in the occurrence of spondylolisthesis. ${ }^{10,12,13}$ The restoration of disc height induces foraminal widening and a ligamentotaxis effect of disc bulging. However, central stenosis by hypertrophied ligamentum flavum and ruptured disc herniation cannot be decompressed by LLIF. Posterior fusion surgery with direct decompression, such as TLIF or PLIF, is preferred for patients with concomitant disc herniation that results from the lack of direct decompression from LLIF. We recently attempted OLIF with spinal endoscopic discectomy. Application of the spinal endoscopic system enables exploration of the endplate, ventral portion of spinal canal, and epidural space and permits removal of ruptured disc particles at the right foramen and epidural space of the central canal. ${ }^{2}$ Endoscopically assisted OLIF results in direct decompression through direct removal of the ruptured disc. ${ }^{2,7}$ Hence, spinal endoscopic discectomy-assisted OLIF has direct and indirect decompression effects that are similar to those of posterior lumbar fusion procedures. Indications for LLIF may also be extended by endoscopic assistance. The incidence of foraminal and extraforaminal herniated discs is reportedly higher in patients with spondylolisthesis. ${ }^{8}$ Therefore, we performed additional direct decompression along with indirect decompression by endoscopically removing the foraminal disc pathology.

Because OLIF usually is performed using the left-side approach with the patient in the lateral decubitus position, spinal endoscopic systems can reach the central canal and right foramen. However, this approach is limited in its use for left foramen pathology. ${ }^{2}$

Discectomy and endplate preparation were performed in a blinded fashion under fluoroscopic $\mathrm{C}$-arm guidance

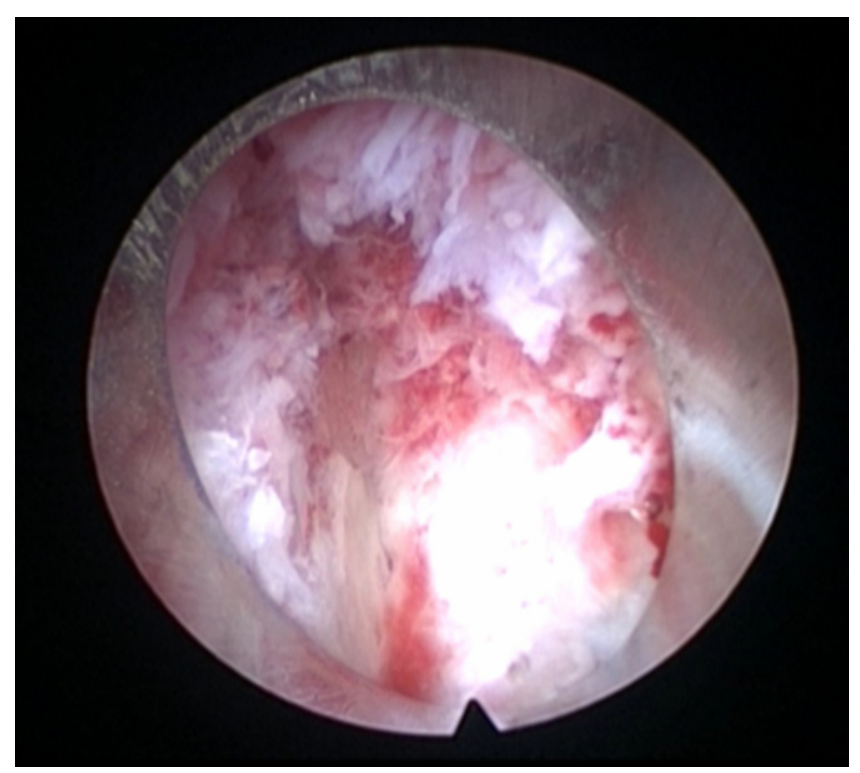

FIG. 4. Intraoperative endoscopic view of the remnant disc materials after blind discectomy during OLIF.

during OLIF or DLIF. During LLIF, the condition of the endplate after blind discectomy cannot be assessed. We checked the condition of endplate preparation for fusion after discectomy using a spinal endoscope (Fig. 4). In 2 patients, substantial remnant disc material and insufficient endplate preparation were observed (Fig. 4). We repeated endplate preparation after endoscopic disc removal in these 2 patients. Other advantages of OLIF with endoscopic discectomy are being able to extend the fusion bed by performing additional endoscopic discectomy and being able to explore the endplate through endoscopic visualization.

To perform optimal endoscopic discectomy with OLIF, previous experience with percutaneous endoscopic transforaminal or interlaminar discectomy is required. If a surgeon is inexperienced in endoscopic discectomy, we recommend that he or she gain additional experience performing endoscopic disc removal of the foramen and central canal with the assistance of an expert spinal endoscopic surgeon after blind discectomy with OLIF. In our patients, additional endoscopic discectomy was performed by an expert endoscopic spine surgeon.

Indirect and direct decompression can be achieved by ALIF with discectomy and removal of osteophytes. Herniated disc particles can be removed directly during the ALIF procedure without using a spinal endoscopic system. ALIF is a complicated procedure that has a long learning curve and the possibility of severe complications, such as abdominal visceral injury resulting in retrograde ejaculation and vascular injury. Posterior fusion surgeries, such as PLIF and TLIF, can accomplish direct decompression when laminectomy, facetectomy, and discectomy are used. Spine surgeons' familiarity with surgical anatomy is another merit of posterior fusion surgery. However, the risk of substantial bleeding, epidural adhesion, and posterior myoligamentous injury are disadvantages of PLIF and TLIF.

Blood loss during LLIF was markedly less and the 
operative time relatively short compared with those of posterior approaches. In our experience, performing endoscopic discectomy during OLIF decreased the amount of bleeding, and the mean operative time required for additional endoscopic discectomy was only 40 minutes. No complications associated with endoscopic procedures were encountered. Lumbar plexus injury is the most serious concern with LLIF., 3,15 Because of the high possibility of lumbar plexus injury during the transpsoas approach for lateral fusion, neurophysiological monitoring is necessary. ${ }^{3,9,15}$ Therefore, OLIF as a modified transpsoas LLIF technique was introduced to decrease the occurrence of lumbar plexus injury by following the oblique trajectory. ${ }^{17}$ The trajectory of OLIF is anterior to the psoas area, and the docking location of the tubular retractor is the safer zone between the aorta and lumbar plexus. ${ }^{16}$ We found only minor injury or irritation of the lumbar plexus in 2 patients during our study. Also, 2 patients presented with only numbness of the left leg that resolved spontaneously within 3 months after surgery.

LLIF, including DLIF and OLIF, preserves posterior anatomical structures (including the lamina, facet, and posterior spinal muscles) and ligamentous structures. Injury to posterior structures and postoperative epidural scar formation after posterior fusion surgery can induce additional problems, such as postoperative back pain. Preservation of posterior anatomical structures might be an advantage of this surgery over posterior fusion procedures. Decreased blood loss is another merit of endoscopically assisted OLIF compared with that seen with the posterior approach. Although endoscopically assisted OLIF has direct and indirect decompressive effects, if patients have stenosis caused by facet hypertrophy, thickening of the ligamentum flavum, or calcified disc herniation, a posterior approach should be considered.

This technique might have some limitations or result in surgical difficulty in the removal of posterior osteophytes, migrated discs, and calcified discs. Spinal endoscopic systems that include an endoscopic drill, punch, and semiflexible forceps were developed recently. The limitations of OLIF are anticipated to be overcome with the help of advanced spinal endoscopic devices.

Our study was limited by the small number of cases. A larger cohort and long-term follow-up are required for the evaluation of outcome in patients after OLIF with endoscopic discectomy.

\section{Conclusions}

OLIF with additional endoscopic discectomy successfully enables direct neural decompression without posterior decompressive procedures. Spinal endoscopic discectomy-assisted OLIF might be an alternative minimally invasive surgical option for properly selected patients. We suggest that endoscopic assistance can overcome the limitations of LLIF.

\section{References}

1. Fairbank JC, Pynsent PB: The Oswestry Disability Index. Spine (Phila Pa 1976) 25:2940-2952, 2000

2. Heo DH, Choi WS, Park CK, Kim JS: Minimally invasive oblique lumbar interbody fusion with spinal endoscope assistance: technical note. World Neurosurg 96:530-536, 2016

3. Houten JK, Alexandre LC, Nasser R, Wollowick AL: Nerve injury during the transpsoas approach for lumbar fusion. J Neurosurg Spine 15:280-284, 2011

4. Kepler CK, Sharma AK, Huang RC, Meredith DS, Girardi FP, Cammisa FP Jr, et al: Indirect foraminal decompression after lateral transpsoas interbody fusion. J Neurosurg Spine 16:329-333, 2012

5. Kim JS, Choi WG, Lee SH: Minimally invasive anterior lumbar interbody fusion followed by percutaneous pedicle screw fixation for isthmic spondylolisthesis: minimum 5-year follow-up. Spine J 10:404-409, 2010

6. Kim JS, Kang BU, Lee SH, Jung B, Choi YG, Jeon SH, et al: Mini-transforaminal lumbar interbody fusion versus anterior lumbar interbody fusion augmented by percutaneous pedicle screw fixation: a comparison of surgical outcomes in adult low-grade isthmic spondylolisthesis. J Spinal Disord Tech 22:114-121, 2009

7. Kim JS, Seong JH: Endoscope-assisted oblique lumbar interbody fusion for the treatment of cauda equina syndrome: a technical note. Eur Spine J 26:397-403, 2017

8. Kim KS, Chin DK, Park JY: Herniated nucleus pulposus in isthmic spondylolisthesis: higher incidence of foraminal and extraforaminal types. Acta Neurochir (Wien) 151:14451450,2009

9. Lykissas MG, Aichmair A, Hughes AP, Sama AA, Lebl DR, Taher F, et al: Nerve injury after lateral lumbar interbody fusion: a review of 919 treated levels with identification of risk factors. Spine J 14:749-758, 2014

10. Moller DJ, Slimack NP, Acosta FL Jr, Koski TR, Fessler RG, Liu JC: Minimally invasive lateral lumbar interbody fusion and transpsoas approach-related morbidity. Neurosurg Focus 31(4):E4, 2011

11. Mummaneni PV, Dhall SS, Eck JC, Groff MW, Ghogawala Z, Watters WC III, et al: Guideline update for the performance of fusion procedures for degenerative disease of the lumbar spine. Part 11: interbody techniques for lumbar fusion. J Neurosurg Spine 21:67-74, 2014

12. Oliveira L, Marchi L, Coutinho E, Pimenta L: A radiographic assessment of the ability of the extreme lateral interbody fusion procedure to indirectly decompress the neural elements. Spine (Phila Pa 1976) 35 (26 Suppl):S331-S337, 2010

13. Ozgur BM, Aryan HE, Pimenta L, Taylor WR: Extreme lateral interbody fusion (XLIF): a novel surgical technique for anterior lumbar interbody fusion. Spine J 6:435-443, 2006

14. Resnick DK, Watters WC III, Sharan A, Mummaneni PV, Dailey AT, Wang JC, et al: Guideline update for the performance of fusion procedures for degenerative disease of the lumbar spine. Part 9: lumbar fusion for stenosis with spondylolisthesis. J Neurosurg Spine 21:54-61, 2014

15. Rodgers WB, Gerber EJ, Patterson J: Intraoperative and early postoperative complications in extreme lateral interbody fusion: an analysis of 600 cases. Spine (Phila Pa 1976) 36:26-32, 2011

16. Silvestre C, Mac-Thiong JM, Hilmi R, Roussouly P: Complications and morbidities of mini-open anterior retroperitoneal lumbar interbody fusion: Oblique lumbar interbody fusion in 179 patients. Asian Spine J 6:89-97, 2012

17. St Clair S, Tan JS, Lieberman I: Oblique lumbar interbody fixation: a biomechanical study in human spines. J Spinal Disord Tech 25:183-189, 2012

\section{Disclosures}

Dr. Kim is a consultant for RIWOspine. 


\section{Author Contributions}

Conception and design: both authors. Acquisition of data: Kim. Analysis and interpretation of data: both authors. Drafting the article: Heo. Critically revising the article: Kim. Reviewed submitted version of manuscript: both authors. Approved the final version of the manuscript on behalf of both authors: Kim. Statistical analysis: Heo. Administrative/technical/material support: Kim.

\section{Correspondence}

Jin-Sung Kim, Department of Neurosurgery, Seoul St. Mary's Hospital, College of Medicine, The Catholic University of Korea, 222 Banpo Daero, Seocho-gu, Seoul 06591, Korea. email: mddavidk@gmail.com. 